\title{
Development of oxybutynin chloride topical gel for overactive bladder
}

\author{
This article was published in the following Dove Press journal: \\ Open Access Journal of Urology \\ I April 20 I I \\ Number of times this article has been viewed
}

\author{
Vincent R Lucente' \\ David R Staskin ${ }^{2}$ \\ Elise $\mathrm{De}^{3}$ \\ 'Institute of Female Pelvic Medicine \\ and Reconstructive Surgery, \\ Allentown, PA, USA; \\ ${ }^{2}$ Division of Urology, \\ St Elizabeth's Medical Center, \\ Tufts University School of Medicine, \\ Boston, MA, USA; ${ }^{3}$ Urological Institute \\ of Northeastern New York, Albany, \\ NY, USA
}

\begin{abstract}
Overactive bladder $(\mathrm{OAB})$ is an age-related syndrome often associated with urinary incontinence. Symptoms of OAB, such as urgency, frequency, and nocturia, can be treated effectively with inhibitors of muscarinic acetylcholine receptors. Antimuscarinic agents promote relaxation of the detrusor muscle and may modulate afferent neuronal signals involved in the regulation of the micturition reflex. Despite the availability of an increasing number of oral antimuscarinic agents, treatment persistence among patients with OAB generally appears to be low. This may be attributed, at least in part, to the common occurrence of anticholinergic adverse effects, such as dry mouth, constipation, and dizziness. Oxybutynin is a well-established antimuscarinic agent that is available in a variety of formulations. Transdermal formulations have been developed to avoid the first-pass hepatic and gastrointestinal drug metabolism responsible for the anticholinergic adverse effects often observed with oral delivery of oxybutynin. Oxybutynin chloride topical gel (OTG) is a formulation of oxybutynin that was approved by the US Food and Drug Administration in January 2009. OTG was the result of a systematic evidence-based effort to develop a formulation that preserves the efficacy of oral oxybutynin formulations while eliminating most of their anticholinergic adverse effects. Additional emphasis was put on creating a transdermal formulation with minimal potential for application-site skin reactions. The formulation and pharmacokinetic properties of OTG are reviewed in the context of recently published efficacy and tolerability data from a large multicenter, placebo-controlled Phase III study.
\end{abstract}

Keywords: oxybutynin topical gel, overactive bladder, transdermal formulation

\section{Introduction}

Overactive bladder (OAB) syndrome is characterized by urinary urgency, typically accompanied by frequency and nocturia. ${ }^{1} \mathrm{OAB}$ is often associated with urinary incontinence, particularly in women. ${ }^{2,3}$ Although it is most common among the elderly, OAB also affects many middle-aged people. ${ }^{2}$ The cause of OAB symptoms is poorly understood because of the complexity of the neuronal circuits that control micturition. ${ }^{4,5}$ Antagonism of muscarinic acetylcholine receptors is currently the only clinically proven mechanism of effective OAB treatment, and antimuscarinic agents, which usually are administered orally, are first-line therapy for patients with OAB. ${ }^{6}$ Oxybutynin, a tertiary amine with anticholinergic and antispasmodic activities, has been used for more than four decades to treat patients with OAB.

Oxybutynin is a competitive muscarinic receptor antagonist with limited selectivity for M3 muscarinic receptors, ${ }^{7}$ which are believed to be the main target in the detrusor muscle of efferent neuronal signals triggering micturition. ${ }^{5}$ In addition to promoting
Correspondence: Vincent R Lucente Institute of Female Pelvic Medicine and Reconstructive Surgery, Hamilton Court Professional Center, 3050 Hamilton Blvd, Suite 200, Allentown, PA, USA 18103 Tel +l 6104359575

$\mathrm{Fax}+\mathrm{I} 6104352763$

Email vlucente@fpminstitute.com
Open Access Journal of Urology 201 I:3 35-42

which permits unrestricted noncommercial use, provided the original work is properly cited. 
detrusor smooth muscle relaxation by blocking local M3 receptors, muscarinic receptor antagonists recently have been suggested to reduce urge sensation by desensitizing afferent neuronal signal transmission from the bladder to the central nervous system. ${ }^{8,9}$

An important limitation of antimuscarinic agents is their association with anticholinergic adverse effects, such as dry mouth, constipation, and blurred vision. ${ }^{10,11}$ These effects are likely a major factor contributing to the poor treatment persistence and medication adherence often observed among patients taking oral antimuscarinics. ${ }^{12,13}$ Clinical studies in patients with OAB demonstrated that various oral formulations of oxybutynin were effective in improving OAB-related symptoms, but caused dry mouth in $17 \%-87 \%$ of study participants who received the drug, with incidences depending on type of formulation, dose, and length of treatment. ${ }^{14}$

Oxybutynin chloride topical gel (OTG) is a novel transdermal formulation of oxybutynin that was approved by the US Food and Drug Administration (FDA) in early 2009. ${ }^{15}$ Results of a large placebo-controlled Phase III study demonstrated that OTG is efficacious and well tolerated, with low incidences of anticholinergic adverse events and application-site skin reactions. ${ }^{16}$ Here, we review the development of OTG, provide previously unpublished data, and discuss its unique formulation and pharmacokinetic properties in the context of available clinical efficacy and tolerability data.

\section{Formulation development}

OTG was developed as a transdermal oxybutynin formulation with the following properties: a formulation strength (oxybutynin concentration) and dose volume compatible with an application surface area large enough to ensure full bioavailability of the therapeutic dose and small enough to allow convenient and efficient application; a composition supporting optimal skin tolerability; and pharmacokinetic properties supporting efficacy comparable with that of available oxybutynin formulations with a once-daily application schedule. OTG was formulated to have a pharmacokinetic profile similar or superior to that of the oxybutynin transdermal delivery system (OXY-TDS), an established antimuscarinic treatment that requires twice-weekly application of a patch. ${ }^{17} \mathrm{~A}$ short-term comparative study suggested that OXY-TDS had efficacy similar to that of immediate-release oral oxybutynin but was associated with a significantly lower incidence of dry mouth than the oral formulation. ${ }^{18} \mathrm{~A}$ study in healthy volunteers further showed that the ratio of $N$-desethyloxybutynin ( $N$-DEO) to oxybutynin plasma exposure levels was approximately 1.3 for OXY-TDS and approximately 4.0 for orally administered extended-release oxybutynin. ${ }^{19}$ Subsequently, it was shown that healthy subjects receiving oxybutynin via transdermal delivery had significantly greater saliva production than those who received an oral formulation. ${ }^{19}$

An initial in vitro study evaluating different formulations of OTG suggested that skin permeation was not significantly affected by formulation strength (ie, oxybutynin concentration in the gel, Tables 1 and 2). Early human studies of OTG evaluating the pharmacokinetic effects of application surface area and formulation strength found that bioavailability generally increased with decreasing formulation strength and increasing application surface area (Table 3, OG04004, OG04007; Figure 1). However, for a given formulation, differences in application surface area had only a modest effect on bioavailability (Table 3, OG03013; Table 4). In addition, formulation strength and application surface area had no effect on the mean $N$-DEO/oxybutynin plasma exposure ratio, which in all relevant studies was consistently 0.9 for single-dose administration of OTG (Table 3, eg, OG3005, OG4007). Single-dose pharmacokinetics also indicated that $1 \mathrm{~g} \mathrm{10 \%}$ OTG produced plasma exposures of oxybutynin and $N$-DEO that were similar to those resulting from OXY-TDS at the normal therapeutic dose $(3.9 \mathrm{mg} /$ day). Furthermore, mathematical simulations using nonlinear regression models predicted comparable steady-state pharmacokinetic profiles for the two formulations (Unpublished data on file, Watson Laboratories, Salt Lake City, UT). Because $1 \mathrm{~g} \mathrm{10 \%}$ OTG appeared to be the formulation most likely to meet all development objectives for OTG, it was chosen for further pharmacokinetic analysis.

\section{Formulation properties of $10 \%$ oxybutynin topical gel}

The FDA-approved OTG formulation consists of $10 \%(\mathrm{w} / \mathrm{w})$ oxybutynin in a semisolid, clear, colorless, and fragrancefree gel that causes no stains on the skin. ${ }^{15}$ One gram of OTG, containing $100 \mathrm{mg}$ oxybutynin, is applied once daily to rotating sites on the abdomen, upper arm or shoulder, and thigh. A single dose of OTG amounts to a volume of only $1.14 \mathrm{~mL}$, which is less than a quarter of a teaspoon. The basis of the gel is a hydroalcoholic solvent (a mixture of water and alcohol) that ensures that the gel dries quickly after application without leaving residues. Additional ingredients are hydroxypropyl cellulose as the gelling agent, glycerin as an emollient that gives the gel a pleasant, smooth feel on the skin, and sodium hydroxide to maintain a $\mathrm{pH}$ of 6 . At this $\mathrm{pH}$, which is within the physiologic $\mathrm{pH}$ range of the skin, oxybutynin exists predominantly as an 
Table I Preclinical studies ${ }^{\mathrm{a}}$

\begin{tabular}{|c|c|c|c|}
\hline Study & Objective & Methods & Main results \\
\hline $\begin{array}{l}\text { ARD-RSR-0779 } \\
\text { (in vitro) }\end{array}$ & $\begin{array}{l}\text { Light absorbance of } \\
\text { OTG versus placebob }\end{array}$ & $\begin{array}{l}\text { Assay: Maximum light absorbance at } 290-700 \mathrm{~nm} \\
\text { Standard: } 100.2 \mathrm{mg} / \mathrm{mL} \text { oxybutynin chloride in ethanol } \\
\text { Test substances: OTG (I0\% oxybutynin), placebo }\end{array}$ & $\begin{array}{l}\text { Major light absorption was not } \\
\text { observed; thus OTG is not } \\
\text { expected to cause phototoxicity }\end{array}$ \\
\hline $\begin{array}{l}\text { Skin flux study } \\
\text { (in vitro) }\end{array}$ & $\begin{array}{l}\text { Skin permeation of } \\
\text { different OTG } \\
\text { formulations }\end{array}$ & $\begin{array}{l}\text { Material: Human cadaver skin } \\
\text { OTG formulations: } 2.2 \%, 4.4 \% \text { (reference), } 6.6 \%, 8.8 \% \text {, } \\
\text { and I } 3.2 \% \text { oxybutynin } \\
\text { Assessment: Mean cumulative permeation } \\
24 \text { hours post application }\end{array}$ & $\begin{array}{l}\text { Mean cumulative permeation } \\
\text { at } 24 \text { hours of } 6.6 \%, 8.8 \% \text {, and } \\
\text { I3.2\% OTG was not significantly } \\
\text { different from that of } 4.4 \% \text { OTG } \\
\text { (see Table } 2 \text { ) }\end{array}$ \\
\hline $\begin{array}{l}\text { ONY000I2 } \\
\text { (animal) }\end{array}$ & $\begin{array}{l}\text { Skin irritation, OTG } \\
(10 \%) \text { versus placebo }\end{array}$ & $\begin{array}{l}\text { Animals: New Zealand White rabbits }(n=6) \\
\text { Treatment: } 23 \text {-hour application on dorsal trunk for } 5 \text { days } \\
\text { Assessment: PII up to } 7 \text { days after last application } \\
\text { (range, 0-8; PII score } \geq 5 \text { indicates irritation) }\end{array}$ & $\begin{array}{l}\text { OTG caused no skin irritation } \\
\text { (PII scores: placebo, 0.5; OTG, } 2.1 \text { ) }\end{array}$ \\
\hline $\begin{array}{l}\text { ONY000I3 } \\
\text { (animal) }\end{array}$ & $\begin{array}{l}\text { Skin sensitization } \\
\text { potential, OTG (10\%) } \\
\text { versus placebo }\end{array}$ & $\begin{array}{l}\text { Animals: Hartley-derived albino guinea pigs }(\mathrm{n}=20) \\
\text { Design: Induction ( } 3 \text { over } 3 \text { weeks), rest }(2 \text { weeks), } \\
\text { challenge test } \\
\text { Challenge test groups: OTG }(\mathrm{n}=10) \text {, placebo }(\mathrm{n}=10) \\
\text { Challenge controls: Untreated animals ( } 5 \text { per test group) } \\
\text { Assessment: Dermal grading system }\end{array}$ & $\begin{array}{l}\text { OTG or placebo elicited no } \\
\text { dermal reactions after induction } \\
\text { and challenge, indicating that } \\
\text { neither OTG nor placebo caused } \\
\text { delayed contact sensitization }\end{array}$ \\
\hline
\end{tabular}

Notes: aData on file, Watson Laboratories, Salt Lake City, UT; 'Placebo is defined as OTG with 0\% oxybutynin.

Abbreviations: OTG, oxybutynin chloride topical gel; PII, Primary Irritation Index.

unprotonated, lipophilic base. Uncharged oxybutynin is absorbed easily by the stratum corneum, the outermost layer of the epidermis. Skin absorption is further aided by the presence of alcohol in the gel.

Once oxybutynin has been absorbed by the skin, it permeates the epidermis before reaching the capillary system of the dermis, which provides access to the systemic circulation. Passive diffusion through the stratum corneum is believed to be the rate-limiting step during gel-based transdermal delivery of lipophilic drugs. ${ }^{20}$ Unpublished pharmacokinetic data show that the release of oxybutynin into the systemic circulation is slow, suggesting that the skin serves as a reservoir from which oxybutynin is released gradually. This reservoir function of the skin is likely responsible for the small peak-to-trough fluctuation in steady-state plasma concentrations of oxybutynin that occurs during once-daily

Table 2 Effect of OTG formulation strength on in vitro skin permeation $^{\mathrm{a}}$

\begin{tabular}{lll}
\hline $\begin{array}{l}\text { OTG formulation } \\
\text { strength, } \\
\% \text { oxybutynin }\end{array}$ & $\begin{array}{l}\text { Cumulative } \\
\text { permeation }\left(\mu \mathrm{g} / \mathrm{cm}^{2}\right) \\
\text { at } \mathbf{2 4} \text { hours, mean } \pm \text { SD }\end{array}$ & $\begin{array}{l}\text { Paired } \text { t-test, } \\
\boldsymbol{P}^{\text {value }}{ }^{\mathrm{b}}\end{array}$ \\
\hline 2.2 & $9.10 \pm 5.35$ & 0.008 \\
4.4 & $14.17 \pm 9.84$ & Control \\
6.6 & $13.37 \pm 9.54$ & 0.718 \\
8.8 & $15.36 \pm 7.41$ & 0.769 \\
13.2 & $18.47 \pm 11.07$ & 0.279 \\
\hline
\end{tabular}

Notes: ${ }^{\mathrm{D} D a t a}$ on file, Watson Laboratories, Salt Lake City, UT; bP $<0.05$ indicates a significant difference versus control (4.4\% oxybutynin).

Abbreviations: OTG, oxybutynin chloride topical gel; SD, standard deviation. dosing with OTG (Figure 2A). Recent single-dose pharmacokinetic studies in healthy adults suggest that the pharmacokinetic profile and bioavailability of oxybutynin are not markedly affected by application of water-based sunscreen before or after OTG application or by taking a shower more than one hour after OTG application. ${ }^{21}$

\section{Clinical efficacy}

Although OTG and OXY-TDS have not been compared in a controlled clinical trial, similarly designed placebo-controlled Phase III studies of each formulation suggested that OTG and OXY-TDS have comparable efficacies. ${ }^{16,22} \mathrm{~A}$ 12-week, double-blind, placebo-controlled Phase III study of OTG enrolled 789 patients with urge or mixed urinary incontinence, many of whom had severe OAB symptoms. The mean number of daily urinary incontinence and nocturia episodes at baseline was 5.4 and 2.5, respectively. On average, patients had 12 micturitions per day, and most patients had voided volumes $>160 \mathrm{~mL}$. The majority of patients $(89.2 \%)$ were women, and almost two-thirds were younger than 65 years. OTG significantly reduced the number of daily incontinence episodes (mean decrease, -3.0 versus placebo, -2.5 ; $P<0.0001$, Figure 3 ) and daily micturitions (mean decrease, -2.7 versus placebo, $-2.0 ; P=0.0017$ ) and significantly increased voided volume (mean increase, $21.0 \mathrm{~mL}$ versus placebo, $3.8 \mathrm{~mL} ; P=0.0018) .{ }^{16}$ Although changes from baseline in the daily number of nocturia events did not differ significantly between treatments in the total study population, patients younger than 65 years achieved significant decreases 
Table 3 Clinical studies in healthy volunteers ${ }^{\mathrm{a}}$

\begin{tabular}{|c|c|c|c|}
\hline Study & Objective & Methods & Main results \\
\hline \multicolumn{4}{|c|}{ Dermatologic studies } \\
\hline $\begin{array}{l}\text { OG05003, } \\
\text { Single-center } \\
(n=45)\end{array}$ & $\begin{array}{l}\text { Cumulative skin } \\
\text { irritation, OTG (10\%) } \\
\text { versus placebo }\end{array}$ & $\begin{array}{l}\text { Design/Treatment: OTG and placebo once daily for } \\
2 \text { I days on contralateral sites of the back } \\
\text { Assessment: Cumulative irritation score (scoring } \\
\text { scale of Berger and Bowman }{ }^{27} \text { ) performed before } \\
\text { first application and } 24 \text { hours after last application }\end{array}$ & $\begin{array}{l}\text { Mean scores: OTG, } 35 \text {; placebo, } 24 \text {; } \\
\text { both scores qualify as class I response } \\
\text { (mild article; no experimental irritation), } \\
\text { indicating absence of cumulative irritation }\end{array}$ \\
\hline $\begin{array}{l}\text { OG05004, } \\
\text { Single-center } \\
(\mathrm{n}=225)\end{array}$ & $\begin{array}{l}\text { Delayed skin } \\
\text { sensitization, OTG } \\
(10 \%) \text { versus placebo }\end{array}$ & $\begin{array}{l}\text { Design: Within-subject randomized, evaluator-blinded } \\
\text { design; induction ( } 9 \text { applications over } 3 \text { weeks), } \\
\text { rest ( } 2 \text { weeks), } 48 \text {-hour challenge application } \\
\text { Treatment: } 0.5 \text { g OTG and placebo application } \\
\text { to } 3 \text {-inch squares }\end{array}$ & $\begin{array}{l}\text { Most subjects had no visible reaction or } \\
\text { erythema } 5 \text { minutes, } 24 \text { hours, } 48 \text { hours, } \\
\text { and } 72 \text { hours post challenge: OTG, } \\
93.0 \%-99.5 \% \text {; placebo: } 94.5 \%-99.0 \% \text {; all } \\
\text { reactions that occurred were slight or mild }\end{array}$ \\
\hline
\end{tabular}

\section{Pharmacokinetic studies}

$\begin{array}{ll}\text { OG03005, } & \text { Single-/multiple-dose } \\ \text { Single-center } & \text { pharmacokinetics, } \\ (n=20) & \text { OTG }(4.4 \%)\end{array}$

OG03013, Bioavailability (single dose), Single-center effect of application surface $(\mathrm{n}=22) \quad$ area, OTG (4.4\%)

OG04004, Bioavailability (single dose), Single-center effect of OTG formulation $(n=20) \quad$ strength

OG04007

Single-cener $(n=22)$
Pharmacokinetic comparison (single dose) OTG versus OXY-TDS
Design: 2-period, single-/multiple-dose, 7-day washout

Dose: 3 g OTG (4.4\% oxybutynin) once daily

Treatment: Single dose on abdomen (day I), multiple doses on rotating sites of abdomen, upper arms/shoulders, and thighs (days 9-15) Assessments: Plasma oxybutynin and N-DEO at predose and during the 72 hours after dosing on days I and I5

Design: 2-period, open-label, randomized,

$\geq 6$-day washout

Treatment: 3 g OTG (4.4\% oxybutynin) applied to $400 \mathrm{~cm}^{2}$ (on I thigh) or $800 \mathrm{~cm}^{2}$ ( $400 \mathrm{~cm}^{2}$ on each thigh)

Assessments: Plasma oxybutynin,

N-DEO over 72 hours post dose

Design: 2-period, open-label, randomized,

$\geq$ 10-day washout

Treatment: Application on abdomen of I g 13.2\% OTG on $133 \mathrm{~cm}^{2}$ or $3 \mathrm{~g} 4.4 \%$ OTG on $400 \mathrm{~cm}^{2}$

Assessments: Plasma oxybutynin,

N-DEO over 72 hours post dose

Design: 4-period, open-label, randomized, 7-day washout Treatments: (A) $3.9 \mathrm{mg} /$ day OXY-TDS,

(B) 3 g 4.4\% OTG, (C) I g $10 \%$ OTG, (D) 3 g 10\% OTG Assessments: Plasma oxybutynin, N-DEO over 72 hours post dose
Single-dose period: Mean N-DEO/

oxybutynin 72-hour exposure ratio was 0.9 Multiple-dose period: Plasma oxybutynin concentrations did not reach steady state; no application-site erythema was observed

Doubling the surface area increased mean oxybutynin AUC [0-72 h] by $12.7 \%$ and mean $C_{\text {max }}$ by $2.7 \%$ (see Table 4); no application-site erythema was observed

The 2 formulations were not bioequivalent Oxybutynin AUC [0-inf] (see Figure I):

$-245 \mathrm{ng} \cdot \mathrm{h} / \mathrm{mL}$ for $3 \mathrm{~g} 4.4 \%$ OTG

$-170 \mathrm{ng} \cdot \mathrm{h} / \mathrm{mL}$ for I g I3.2\% OTG

Dose-normalized oxybutynin AUC [0-144 h]: (A) 176, (B) 325, (C) 219, (D) $499 \mathrm{ng} \cdot \mathrm{h} / \mathrm{mL}$ N-DEO/oxybutynin exposure ratio: OXY-TDS, I.I; OTG, 0.9

Note: a ata on file, Watson Laboratories, Salt Lake City, UT.

Abbreviations: AE, adverse event; AUC, area under the concentration-time curve; N-DEO, N-desethyloxybutynin; OTG, oxybutynin chloride topical gel; OXY-TDS, oxybutynin transdermal system.

A

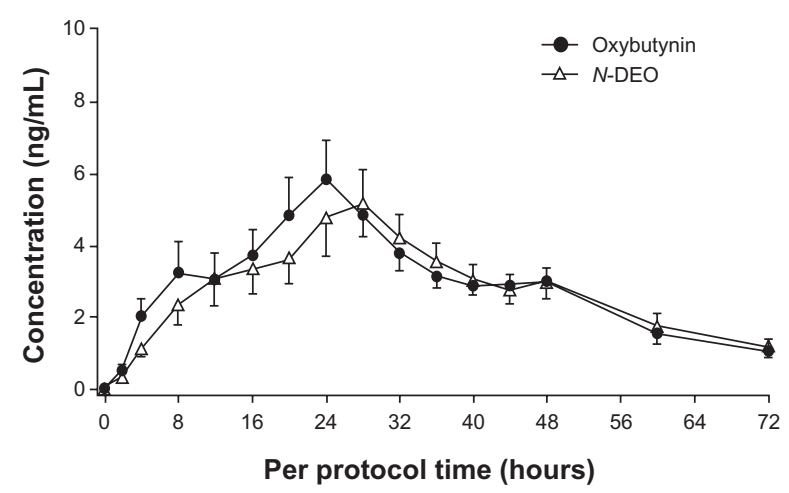

B

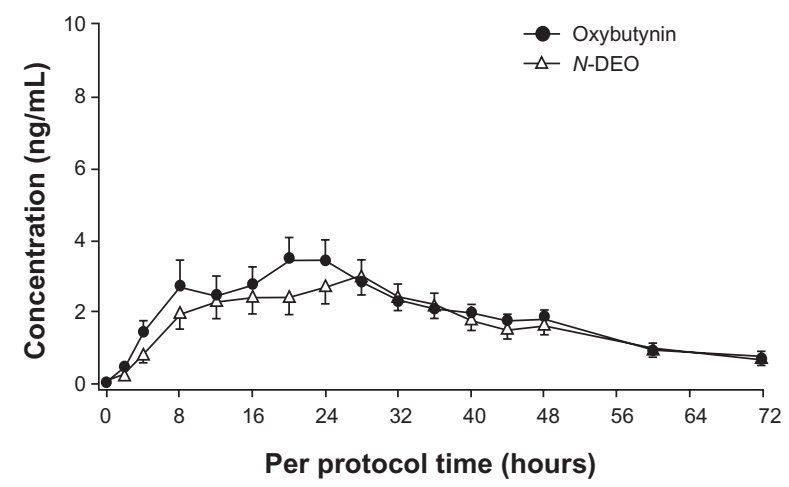

Figure I Mean oxybutynin and N-DEO plasma concentrations in healthy adults after a single dose of (A) $3 \mathrm{~g} 4.4 \%$ OTG or (B) I g I3.2\% OTG. Error bars indicate standard errors of the mean.

Abbreviations: N-DEO, N-desethyloxybutynin; OTG, oxybutynin chloride topical gel. 
Table 4 Effect of application surface area on oxybutynin bioavailability $(n=21)$

\begin{tabular}{|c|c|c|}
\hline Parameter, mean (SD) & $400 \mathrm{~cm}^{2}$ area & $800 \mathrm{~cm}^{2}$ area \\
\hline AUC [0-72 h], $\mathrm{ng} \cdot \mathrm{h} / \mathrm{mL}$ & |26.9| (83.69) & I 43.04 (8I.30) \\
\hline $\mathrm{C}_{\max }, \mathrm{ng} / \mathrm{mL}$ & $3.70(2.95)$ & $3.80(2.32)$ \\
\hline $\mathrm{T}_{\max }, \mathrm{h}$ & $48.57(14.33)$ & $43.81(15.82)$ \\
\hline
\end{tabular}

Abbreviations: AUC, area under the plasma concentration-time curve; $C_{\max }$ maximum measured plasma concentration; SD, standard deviation; $T_{\max }$, time to maximum measured plasma concentration.

in nocturia episodes with OTG versus placebo (mean decrease, -0.91 versus $-0.72 ; P=0.0363){ }^{16}$

\section{Steady-state pharmacokinetics of OTG versus OXY-TDS}

A definitive comparison of the steady-state pharmacokinetic profiles of OTG (1 g, 10\% oxybutynin) and OXY-TDS (effective dose, oxybutynin $3.9 \mathrm{mg} /$ day) was conducted in 22 healthy adults aged $18-45$ years. ${ }^{23}$ According to a two-period randomized crossover design, subjects received OTG for 18 consecutive days followed or preceded by five applications of OXY-TDS every 3.4-4.0 days. The two treatment periods were separated by a washout period of at least two weeks. Blood samples for pharmacokinetic analysis were taken during the last four days of dosing. The two transdermal delivery systems produced concentration-time curves for oxybutynin with similar mean four-day plasma exposures (OTG, $322 \mathrm{ng} \cdot \mathrm{h} / \mathrm{mL}$; OXY-TDS, $313 \mathrm{ng} \cdot \mathrm{h} / \mathrm{mL}$ ) and mean average concentrations (OTG, $3.35 \mathrm{ng} / \mathrm{mL}$; OXY-TDS, $3.26 \mathrm{ng} / \mathrm{mL}$, Figure 2A, Table 5). $N$-DEO steady-state plasma concentrations were consistently lower with OTG than with OXY-TDS, regardless of when the blood samples were taken (Figure 2B). Consequently, four-day $N$-DEO/oxybutynin exposure ratios were approximately 0.8 for OTG and approximately 1.1 for
OXY-TDS (Table 5). The low $N$-DEO plasma concentrations for OTG compared with those for OXY-TDS may be attributable to the presence of ethanol in the OTG formulation. Because ethanol is known to inhibit cytochrome $\mathrm{P} 450$ activity, ethanol absorbed by the skin is likely to slow the conversion of oxybutynin to $N$-DEO by dermal cytochrome P450. Additional pharmacokinetic analyses in healthy volunteers found negligible differences in steady-state exposure levels between various FDA-approved application-site locations. ${ }^{24}$

\section{Safety Skin tolerability}

An important objective of OTG development was the creation of a gel with excellent skin tolerability. OXY-TDS has been shown to be efficacious and associated with low incidences of anticholinergic adverse events, but results of clinical studies in patients with $\mathrm{OAB}$, including a community-based openlabel study, indicated that OXY-TDS can cause pruritus, erythema, and contact dermatitis in a minority of treated patients. ${ }^{22,25,26}$ Notably, in a placebo-controlled study of OXYTDS in patients with OAB, application-site pruritus was observed not only in $16.8 \%$ of patients who received oxybutynin patches but also in $6.1 \%$ of those who received placebo patches..$^{22}$ This suggested that skin occlusion, desquamation, and delayed contact sensitization possibly caused by patch materials may be major factors contributing to the relatively high incidence of application-site skin reactions with OXY-TDS. Gel-based formulations, such as OTG, largely exclude the possibility of skin occlusion and desquamation. To minimize the potential for delayed contact sensitization, OTG was formulated to contain no permeation enhancer.

Animal studies in New Zealand White rabbits and albino guinea pigs provided early evidence that OTG has no

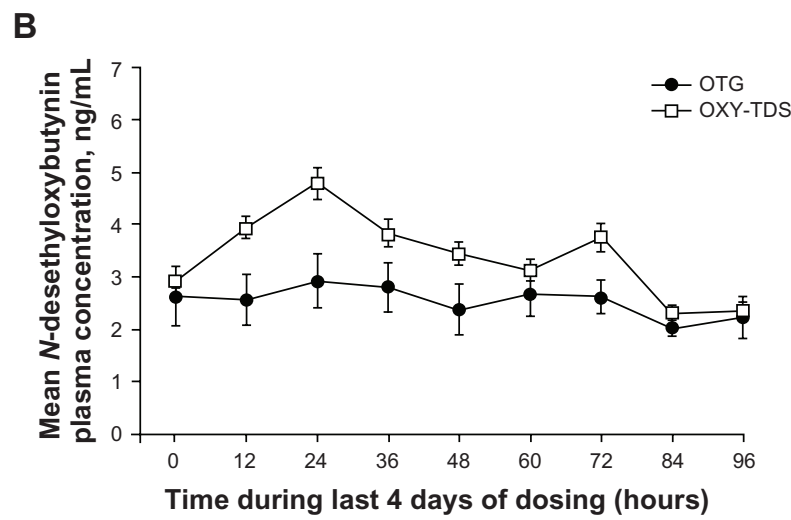

Figure 2 Mean oxybutynin (A) and N-DEO (B) plasma concentrations at steady state in healthy adults treated with OTG or OXY-TDS. Error bars indicate standard errors of the mean.

Notes: Copyright (C 2009. Elsevier. Reprinted with permission from Staskin DR, Dmochowski RR, Sand PK, et al. Efficacy and safety of oxybutynin chloride topical gel for overactive bladder: a randomized, double-blind, placebo controlled, multicenter study. J Urol. 2009;18I (4): I764-1772. ${ }^{16}$

Abbreviations: N-DEO, N-desethyloxybutynin; OTG, oxybutynin chloride topical gel; OXY-TDS, oxybutynin transdermal system. 


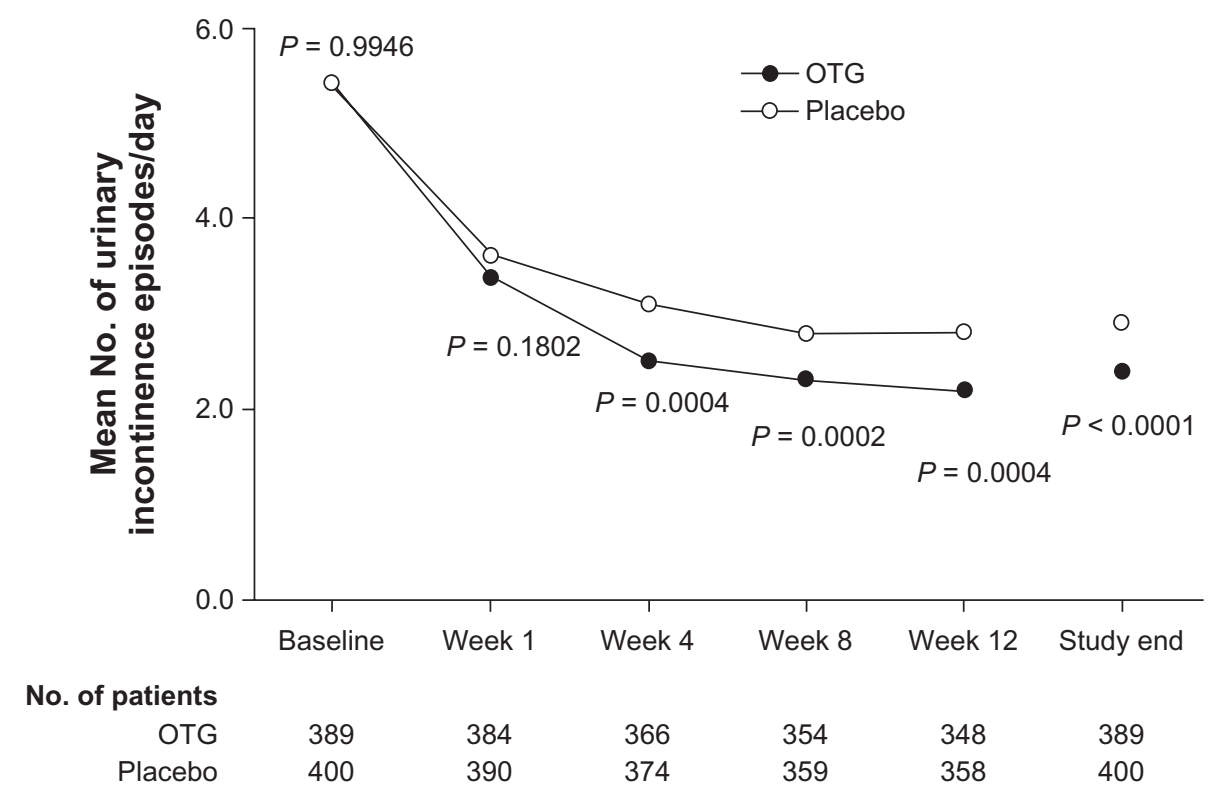

Figure 3 Mean change from baseline in daily urinary incontinence episodes. $P$ values were derived from analysis of variance of baseline data and from analysis of covariance of postbaseline data. Last observations were carried forward for study end only.

Notes: Copyright (C) 2009. Informa Healthcare. Reprinted with permission from Staskin DR, Robinson D. Oxybutynin chloride topical gel: a new formulation of an established antimuscarinic therapy for overactive bladder. Expert Opin Pharmacother. 2009;10:3103-31।11.29

Abbreviations: OTG, oxybutynin chloride topical gel.

propensity to cause skin irritation or delayed contact sensitization (Table 1). Further evidence was provided by the results of two placebo-controlled dermatologic Phase I studies in healthy volunteers (Table 3). Mean cumulative skin irritation scores in 41 subjects treated with OTG and placebo on contralateral sites of the back were substantially lower than 50, irrespective of treatment (Table 3, OG0503). Only scores of 50 or higher are considered evidence of cumulative irritation. ${ }^{27}$ Delayed skin sensitization was assessed in 201 adults treated with OTG and placebo using a within-person randomization scheme. After nine applications over a period of three weeks and a subsequent rest period of two weeks, a final challenge application was performed followed by 72 hours of skin assessment. The percentage of subjects with any visible skin reactions at any time of assessment was $7 \%$ or lower for OTG and 5.5\% or lower for placebo (Table 3,

Table 5 Steady-state pharmacokinetics of oxybutynin chloride topical gel and oxybutynin transdermal delivery system

\begin{tabular}{lll}
\hline Parameter, mean (SD) & $\begin{array}{l}\text { OTG } \\
(\mathbf{n}=\mathbf{2 0})\end{array}$ & $\begin{array}{l}\text { Oxybutynin } \\
\text { TDS }(\mathbf{n}=\mathbf{2 0})\end{array}$ \\
\hline Oxybutynin AUC [0-96 h], ng $\cdot \mathrm{h} / \mathrm{mL}$ & $32 \mathrm{I} .7(\mathrm{II} 2.3)$ & $3 \mathrm{I} 2.5(67.6)$ \\
N-DEO AUC [0-96 h], $\mathrm{ng} \cdot \mathrm{h} / \mathrm{mL}$ & $246.4(97.0)$ & $338.0(1 \mathrm{I} 6.9)$ \\
Ratio, N-DEO/oxybutynin [0-96 h] & $0.77(0.19)$ & $1.07(0.22)$ \\
\hline
\end{tabular}

Abbreviations: AUC, area under the plasma concentration-time curve; $\mathrm{N}$-DEO, N-desethyloxybutynin; OTG, oxybutynin chloride topical gel; $\mathrm{SD}$, standard deviation; TDS, transdermal delivery system.
OG05004). In vitro data further showed that OTG does not absorb light at 290-700 nm (Table 1, ARD-RSR-0779). Therefore, OTG is unlikely to have phototoxic effects on the skin.

Overall, favorable skin tolerability of OTG was also suggested by the results of the Phase III study. ${ }^{16}$ Of the 389 patients treated with OTG, 5.4\% reported application-site skin reactions adverse events (versus 1.0\% for placebo) and $2.1 \%$ developed application-site pruritus adverse events (versus $0.8 \%$, placebo; Table 6). Application-site skin reactions were given as a reason for treatment discontinuation by three patients $(0.8 \%)$ in the OTG group and one patient $(0.3 \%)$ in the placebo group. Few patients experienced application-site erythema, with percentages similar for OTG (1.3\% over all visits) and placebo ( $0.9 \%$ over all visits). At the final visit of the study, $97.4 \%$ of patients in the OTG group and $98.7 \%$ of those in the placebo group were free of erythema. ${ }^{16}$

\section{Anticholinergic adverse effects}

Results of the 12-week, placebo-controlled Phase III study suggest that OTG has a low propensity for causing anticholinergic adverse events. ${ }^{16}$ Dry mouth was the only treatment-related anticholinergic adverse event that occurred in more than $2 \%$ of patients who received OTG and the only one that occurred significantly more often with OTG than with placebo (OTG, 6.9\%; placebo, 2.8\%; $P=0.006$ ); headache, dizziness, and constipation occurred rarely (Table 6). The overall incidence of dry mouth reported for OTG was 
Table 6 Adverse events reported during a I2-week double-blind Phase III study

\begin{tabular}{|c|c|c|c|}
\hline No. of patients (\%) & $\begin{array}{l}\text { OTG } \\
(n=389)\end{array}$ & $\begin{array}{l}\text { Placebo } \\
(n=400)\end{array}$ & $P$ value \\
\hline$\geq \mathrm{IAE}$ & $221(56.8)$ & $193(48.3)$ & $0.0160^{\mathrm{a}}$ \\
\hline$\geq \mathrm{I}$ treatment-related $\mathrm{AE}$ & $73(18.8)$ & $45(11.3)$ & $0.003 I^{a}$ \\
\hline$\geq I$ serious $A E$ & $7(1.8)$ & $10(2.5)$ & $0.498 I^{a}$ \\
\hline $\begin{array}{l}\geq 1 \text { treatment-related } \\
\text { serious } A E\end{array}$ & 0 & 0 & \\
\hline $\begin{array}{l}\text { AE resulting in study } \\
\text { withdrawal } \\
\text { Treatment-related AEs } \\
\text { reported by } \geq 1 \% \text { of } \\
\text { patients in OTG group }\end{array}$ & $19(4.9)$ & $13(3.3)$ & $0.2446^{\mathrm{a}}$ \\
\hline Dry mouth & $27(6.9)$ & II (2.8) & $0.0060^{\mathrm{a}}$ \\
\hline Application-site pruritus & $8(2.1)$ & $3(0.8)$ & $0.1176^{\mathrm{a}}$ \\
\hline Application-site dermatitis & $7(1.8)$ & $\mathrm{I}(0.3)$ & $0.0358^{\mathrm{b}}$ \\
\hline Headache & $6(1.5)$ & II (2.8) & $0.2428^{a}$ \\
\hline Constipation & $5(1.3)$ & $4(1.0)$ & $0.7494^{b}$ \\
\hline Dizziness & $6(1.5)$ & $2(0.5)$ & $0.1719^{\mathrm{b}}$ \\
\hline Pruritus & $5(1.3)$ & $5(1.3)$ & $1.0000^{\mathrm{b}}$ \\
\hline
\end{tabular}

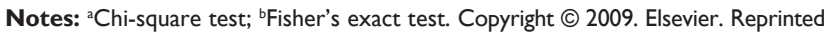
with permission from Staskin DR, Dmochowski RR, Sand PK, et al. Efficacy and safety of oxybutynin chloride topical gel for overactive bladder: A randomized, double-blind, placebo controlled, multicenter study. J Urol. 2009;181 (4): 1764-1772. ${ }^{16}$

Abbreviations: AE, adverse event; OTG, oxybutynin chloride topical gel.

similar to that observed for OXY-TDS in two placebo-controlled Phase III studies ${ }^{22,25}$ and was substantially smaller than that reported for oral oxybutynin in comparable studies. ${ }^{14}$

\section{Health-related quality of life}

Improving health-related quality of life (HRQoL) is an important goal of antimuscarinic treatment that requires efficacy and favorable tolerability. Because HRQoL depends highly on patient perception, it is likely to have a strong influence on treatment persistence and medication adherence. OXY-TDS is one of few antimuscarinic treatments demonstrated to promote significant improvement in HRQoL. ${ }^{10,26}$ In the Phase III study, patients completed two questionnaires commonly used to evaluate HRQoL in patients with urinary conditions, ie, the five-item Incontinence Impact Questionnaire and the 10-domain King's Health Questionnaire. Incontinence Impact Questionnaire responses showed that OTG compared with placebo significantly improved total score $(P=0.0005)$ and emotional health, social relationships, travel, and physical activity scores $(P<0.01)$. Improvement in HRQoL associated with OTG treatment also was observed with the King's Health Questionnaire. Compared with placebo, OTG had significant positive effects on incontinence impact, symptom severity, role limitations, personal relationships, severity (coping) measures, and sleep/energy $(P<0.05){ }^{28}$

\section{Risk of person-to-person transference}

Many potential recipients of OTG are elderly people with OAB who may require assistance. Because OTG is absorbed readily by the skin, caregivers who routinely apply the gel to patients with $\mathrm{OAB}$ are advised to consider safety precautions, such as avoiding direct contact with the gel, particularly if they are sensitive to anticholinergic agents. A recent pharmacokinetic study investigated the degree of oxybutynin transference from treated to untreated subjects through skin-to-skin contact at the application site. ${ }^{21}$ Healthy couples consisting of an untreated and a treated subject performed vigorous 15-minute skin-to-skin contact at the OTG application site one hour after application. The observed degree of transference generally was small, suggesting that the potential for drug transference of clinically relevant doses is small, even under the rigorous, highly unrealistic experimental conditions of the study. In most cases, transference was prevented completely if the application site was covered with clothing during contact. In the few cases in which transference occurred despite clothing, exposure levels were marginal. ${ }^{21}$

\section{Conclusion}

OTG is a novel transdermal formulation that combines the established efficacy of oxybutynin with a tolerability profile that is unprecedented for this agent and characterized by low incidences of anticholinergic adverse events and applicationsite skin reactions. OTG has a pharmacokinetic profile similar to that of OXY-TDS but produces lower $N$-DEO plasma concentrations than the patch delivery system. OTG showed little propensity to cause dry mouth, the only treatment-related anticholinergic event that occurred more often with OTG than with placebo in a Phase III study of patients with OAB. The novel gel-based formulation also avoids most of the application-site skin reactions associated with the patch delivery system. Administration of OTG is convenient, given that OTG has a once-daily application schedule, small application volume, and short drying time. Clinically significant person-to-person transference is possible, but only under conditions of vigorous contact that are unlikely to apply to real-life situations. The efficacy, tolerability, and convenience of OTG likely contributed to the significant and wide-ranging improvements in HRQoL reported by patients with OAB in a Phase III study of OTG. In summary, the available pharmacokinetic and clinical evidence suggests that OTG can provide unique benefits to patients with OAB seeking effective antimuscarinic treatment with a minimum of adverse effects. Growing experience in clinical practice will determine whether this prediction is fully borne out. 


\section{Disclosure/acknowledgments}

VRL is a consultant for Allergan, AMS, Bard, Ethicon, Kimberly-Clark, and Watson, and has received grants from Ethicon and Kimberly-Clark; DRS is a consultant for Allergan, Astellas, GlaxoSmithKline, and Pfizer, and a speaker for Allergan, Astellas, GlaxoSmithKline, Pfizer, and Watson; ED has been a principal investigator in clinical studies for Allergan and Watson, a speaker for Allergan and Pfizer, a consultant on an advisory board for Astellas and AMS, a grant recipient for an academic project for Astellas, and a surgical trainer at AMS. Roland Tacke, $\mathrm{PhD}$, and Candace Lundin, DVM, MS, of Scientific Connexions (Newtown, PA, USA) provided writing support and editorial assistance, which was funded by Watson Pharma, Inc.

\section{References}

1. Abrams P, Cardozo L, Fall M, et al. The standardisation of terminology in lower urinary tract function: Report from the standardisation subcommittee of the International Continence Society. Urology. 2003; 61(1):37-49.

2. Stewart WF, Van Rooyen JB, Cundiff GW, et al. Prevalence and burden of overactive bladder in the United States. World J Urol. 2003;20(6): 327-336.

3. Milsom I, Irwin DE. A cross-sectional, population-based, multinational study of the prevalence of overactive bladder and lower urinary tract symptoms: Results from the EPIC study. Eur Urol. 2007;6:4-9.

4. Gillespie JI, van Koeveringe GA, de Wachter SG, de Vente J. On the origins of the sensory output from the bladder: The concept of afferent noise. BJU Int. 2009;103(10):1324-1333.

5. Abrams P, Andersson KE. Muscarinic receptor antagonists for overactive bladder. BJU Int. 2007;100(5):987-1006.

6. Thomas L, Culley EJ. Overactive bladder disease: The urge for better therapies. J Manag Care Pharm. 2008;14(4):381-386.

7. Chapple CR. Muscarinic receptor antagonists in the treatment of overactive bladder. Urology. 2000;55(5A Suppl):33-46.

8. Masuda H, Kim YT, Tyagi S, Chancellor MB, de Miguel F, Yoshimura N. Local effects of antimuscarinics. Urol Clin North Am. 2006;33(4): 511-518, ix-x.

9. Hedlund P, Streng T, Lee T, Andersson KE. Effects of tolterodine on afferent neurotransmission in normal and resiniferatoxin treated conscious rats. J Urol. 2007;178(1):326-331.

10. Chapple CR, Khullar V, Gabriel Z, Muston D, Bitoun CE, Weinstein D. The effects of antimuscarinic treatments in overactive bladder: An update of a systematic review and meta-analysis. Eur Urol. 2008;54(3):543-562.

11. Staskin DR, Macdiarmid SA. Using anticholinergics to treat overactive bladder: The issue of treatment tolerability. Am J Med. 2006; 119(3 Suppl 1):9-15.

12. Basra RK, Wagg A, Chapple C, et al. A review of adherence to drug therapy in patients with overactive bladder. BJU Int. 2008;102(7): 774-779.

Open Access Journal of Urology

\section{Publish your work in this journal}

The Open Access Journal of Urology is an international, peer-reviewed, open access journal publishing original research, reports, editorials, reviews and commentaries on all aspects of adult and pediatric urology in the clinic and laboratory including the following topics: Pathology, pathophysiology of urological disease; Investigation and treatment of
13. D’Souza AO, Smith MJ, Miller LA, Doyle J, Ariely R. Persistence, adherence, and switch rates among extended-release and immediaterelease overactive bladder medications in a regional managed care plan. J Manag Care Pharm. 2008;14(3):291-301.

14. Appell RA. Pharmacotherapy for overactive bladder: An evidence-based approach to selecting an antimuscarinic agent. Drugs. 2006; 66(10): 1361-1370.

15. GELNIQUE (oxybutynin chloride) $10 \%$ gel [Prescribing information]. Corona, CA: Watson Pharmaceuticals Inc; 2009.

16. Staskin DR, Dmochowski RR, Sand PK, et al. Efficacy and safety of oxybutynin chloride topical gel for overactive bladder: A randomized, double-blind, placebo controlled, multicenter study. J Urol. 2009; 181(4):1764-1772.

17. Oxytrol ${ }^{\circledR}$ oxybutynin transdermal system [Prescribing information]. Corona, CA: Watson Pharmaceuticals Inc; 2006.

18. Davila GW, Daugherty CA, Sanders SW. A short-term, multicenter, randomized double-blind dose titration study of the efficacy and anticholinergic side effects of transdermal compared to immediate release oral oxybutynin treatment of patients with urge urinary incontinence. J Urol. 2001;166(1):140-145.

19. Appell RA, Chancellor MB, Zobrist RH, Thomas H, Sanders SW. Pharmacokinetics, metabolism, and saliva output during transdermal and extended-release oral oxybutynin administration in healthy subjects. Mayo Clin Proc. 2003;78(6):696-702.

20. Roberts MS, Cross SE, Anissimov YG. Factors affecting the formation of a skin reservoir for topically applied solutes. Skin Pharmacol Physiol. 2004;17(1):3-16.

21. Dmochowski RR, Newman DK, Sand PK, et al. Pharmacokinetics of oxybutynin chloride topical gel: effects of application site, showering, sunscreen, and person-to-person transference. Clin Drug Investig. 2011; In press.

22. Dmochowski RR, Davila GW, Zinner NR, et al. Efficacy and safety of transdermal oxybutynin in patients with urge and mixed urinary incontinence. J Urol. 2002;168(2):580-586.

23. Caramelli KE, Staskin DR, Volinn W. Steady-state pharmacokinetics of an investigational oxybutynin topical gel in comparison with oxybutynin transdermal system. J Urol. 2008;179(4):513-514.

24. Caramelli KE, Thomas H, Stanworth S, Hoel G. Steady-state bioavailability of oxybutynin topical gel at 3 different application sites. Poster presented at the Annual Senior Care Pharmacy Meeting of the American Society of Consultant Pharmacists, November 19-22, 2008, New Orleans, LA.

25. Dmochowski RR, Sand PK, Zinner NR, Gittelman MC, Davila GW, Sanders SW. Comparative efficacy and safety of transdermal oxybutynin and oral tolterodine versus placebo in previously treated patients with urge and mixed urinary incontinence. Urology. 2003;62(2):237-242.

26. Sand P, Zinner N, Newman D, et al. Oxybutynin transdermal system improves the quality of life in adults with overactive bladder: A multicentre, community-based, randomized study. BJU Int. 2007; 99(4):836-844.

27. Berger RS, Bowman JP. A reappraisal of the 21-day cumulative irritation test in man. J Toxicol Cutaneous Ocul Toxicol. 1982;1(2):109-115.

28. Newman DK, Hanno PM, Dmochowski RR, et al. Effects of oxybutynin chloride topical gel on health-related quality of life in adults with overactive bladder: A randomized, double-blind, placebo-controlled study. Clinical Medicine Insights: Therapeutics. 2010;2:889-896.

29. Staskin DR, Robinson D. Oxybutynin chloride topical gel: a new formulation of an established antimuscarinic therapy for overactive bladder. Expert Opin Pharmacother. 2009;10:3103-3111.

\section{Dovepress}

urological disease; Pharmacology of drugs used for the treatment of urological disease. The manuscript management system is completely online and includes a very quick and fair peer-review system, which is all easy to use. Visit http://www.dovepress.com/testimonials.php to read real quotes from published authors. 